Review

\title{
Historical Perspective and Evaluation of the Mechanisms by which Melatonin Mediates Seasonal Reproduction in Mammals
}

\author{
Russel J. Reiter*1, ${ }^{\text {, Dun-Xian Tan' }}{ }^{1}$, Ramaswamy Sharma ${ }^{1}$ \\ ${ }^{1}$ Department of Cell Systems and Anatomy, UT Health San Antonio, San Antonio, Texas 78229 \\ USA \\ ${ }^{2}$ Department of Molecular Genetics, University of Lodz, Lodz, Poland \\ *Correspondence: reiter@uthscsa.edu, Tel: + 012105673859.
}

Running title: Pineal, melatonin and seasonal reproduction

Received: November 2, 2018; Accepted: November 20, 2018

\begin{abstract}
The discovery of melatonin and its photoperiod-regulated circadian rhythm were important milestones in defining the events associated with the regulation of seasonal reproduction in both short-day and long-day breeding mammals. By means of the seasonal changes in the duration of the nocturnal melatonin rise, which provides both clock and calendar information, animals adjust their reproductive state to the appropriate time of year. Thus, melatonin dictates the proper season for mating which ensures the optimal time for delivery of offspring. The photoperiodic information is transduced into a chemical messenger, melatonin, in the pineal gland. The initial studies related to the importance of day length and the melatonin message in impelling seasonal reproduction involved the use of photoperiod-sensitive rodents, especially several long-day breeding hamster species. Since then, a large group of interested reproductive biologists have extended these findings to numerous other mammals including short-day breeding ungulates. Moreover, critical information related to the molecular processes at the level of the pars tuberalis of the anterior pituitary and the mediobasal hypothalamus has been provided. In this scheme, the pars tuberalis, until recently an almost ignored portion of the adenohypophysis, has been identified as a critical intermediate between the melatonin signal and the functional state of the reproductive organs. It is somewhat ironic that two organs, the pineal gland and the pars tuberalis, which suffered with the image of vestigiality for so long have now been identified as unequivocally essential for this most basic and important function, i.e., regulating seasonal reproduction.
\end{abstract}

Key words: cerebrospinal fluid; tanycytes; pars tuberalis; tuberalins; retrograde signals; anterograde signals; thyroid stimulating hormone; pars distalis; median eminence. 


\section{INTRODUCTION}

Even before melatonin was discovered in the bovine pineal gland by Lerner and colleagues in 1958 (1), there was evidence, albeit not very compelling, that the pineal, via an undefined secretory product, influenced reproductive physiology in some vertebrates. In books published in 1954, one by Kitay and Altschule (2) and a second by Thieblot and LeBars (3), the authors concluded that one function of the pineal gland is to modulate the reproductive status of vertebrates. This conclusion was primarily based on observations that surgical removal of the pineal gland from mammals and birds sometimes slightly enhanced pubertal onset or growth of the reproductive organs $(4,5)$ and the fact that pineal tumors in humans seem to alter their reproductive status (6). These reports suffered from major shortcomings, however; notably, the investigators that reported on the animal studies were unaware of the importance of the light:dark cycle in controlling the metabolic activity of the pineal gland (so they never considered it as an important variable) and, secondly, the studies were often performed using non-photosensitive (in terms of reproduction) species, e.g., the laboratory rat, where the loss of the pineal gland has no or barely detectable effects on the growth of the peripheral reproductive organs $(7,8)$.

Interestingly, when Lerner and co-workers (1) undertook the task of isolating and identifying the pineal factor that mediates the effects of this gland, their interest was not related to the supposed actions of the pineal or reproductive functions. Rather, being dermatologists, they were interested in determining how the pineal gland influenced skin pigmentation. The stimulus for this time-consuming investigation was a 1918 report by McCord and Allen (9), which noted that dark-skin tadpoles immediately blanched when they were fed macerated bovine pineal tissue. After a tremendous effort which involved the extraction of 250,000 bovine pineal glands, Lerner et al. (1) isolated and identified a serotonin derivative that they named melatonin ("mela" for its effects on amphibian melanophores and "tonin" because it is a derivative of serotonin). This work, unknown to the group at the time, was hampered by the use of pineal glands collected from cows that were surely killed during the light period, when melatonin levels are at their nadir. After its isolation, Lerner and Case (10) found that melatonin did not significantly influence human skin pigmentation so they almost abandoned research on melatonin, a molecule now known to have many other important actions in mammals including humans (11) with marked effects on cutaneous keratinocytes (12). Had Lerner realized the essential functions of melatonin in the skin, other than influencing pigmentation, it seems likely that he would have more enthusiastically continued his research on the serotonin derivative.

The isolation and identification of melatonin (1) was quickly followed by studies related to its synthesis $(13,14)$ and metabolism (15). The results of these investigations established that melatonin synthesis is strongly linked to the light:dark environment (16-19), a finding that was foreshadowed by reports that the morphology of the pineal changes as a function of light exposure (20-22). At the time, the nocturnal production of melatonin in the pineal gland was believed to be controlled by a nighttime rise in the melatonin-forming enzyme, hydroxyindoleO-methyltransferase (HIOMT) (23). This was later invalidated when it was reported that HIOMT (now referred to as acetylserotonin methyltransferase or ASMT) activity remained stable throughout the light:dark cycle and the enzyme that acetylates serotonin, $\mathrm{N}$-acetyltransferase (NAT), is most influential in determining the nocturnal rise in pineal melatonin synthesis (24).

While the pineal production of melatonin was well documented by the studies summarized above, it was roughly a decade later that a variation in blood melatonin levels were found to correlate with pineal synthesis of the indoleamine (25-27). As in the pineal gland, serum levels 
of melatonin are elevated at night and low during the light period supporting the likelihood that after its production in the pineal gland, at least part of the melatonin produced is quickly discharged into the rich vascular network within the gland. The strong correlation between pineal and blood (and cerebrospinal fluid) concentrations of melatonin has led to the conclusion that the pineal does not store residual quantities of its secretory product, a feature common to most endocrine glands, e.g., the par distalis of the pituitary.

\section{DEFINITION OF THE ASSOCIATION OF THE PINEAL GLAND AND MELATONIN WITH REPRODUCTION}

As noted above, in 1960 it had been suspected for several decades that the activity of the pineal gland was somehow involved in regulating reproductive physiology (2-5). The evidence for this, as mentioned, however, was weak and inconsistent, likely related to the following: a) the investigators were unaware of the importance of the light:dark cycle in determining the metabolic and secretory activity of the pineal gland and b) the experiments were often performed using photoinsensitive species in terms of their reproductive capability.

Shortly after its discovery, when melatonin became commercially available, the latter problem was propagated. Thus, when the highly inbred albino rats, a species that is non-seasonal and almost totally insensitive to pineal manipulations or melatonin administration, were injected with melatonin daily for prolonged periods, the injections were essentially inconsequential in modifying reproductive function $(28,29)$. While some changes were measurable, it is unlikely that they would have significantly compromised the reproductive efficiency of the animals. Very soon, however, one rodent species was identified in which the reproductive axis was found to be exquisitely sensitive to perturbations involving the pineal gland and manipulations of the photoperiod. Thus, when Syrian hamsters (Mesocricetus auratus) were exposed to short days (which eventually were found to be less than 12 hours of light daily), their neuroendocrinereproductive axis collapsed $(30,31)$; they became totally reproductively incompetent. This occurred in both males and females (32). As illustrated in Fig. 1, under long photoperiods (summer-type light:dark cycles), male Syrian hamsters are reproductively capable with large testes that exhibit active spermatogenesis. Female Syrian hamsters experience a similar atrophy of their reproductive organs after short day exposure with morphological changes in the ovary indicative of the lack of ovulation, a reduction in the size of the uterus and vaginal acyclicity. In both genders, surgical removal of the pineal gland (33) or any procedure that deprives the pineal of its sympathetic neural input, e.g., superior cervical ganglionectomy, interrupting the nervi conari as they enter the pineal gland, disconnecting the preganglionic fibers from the superior cervical ganglia, etc., prevents the short day-mediated reproductive regression $(30,32,34,35)$. 


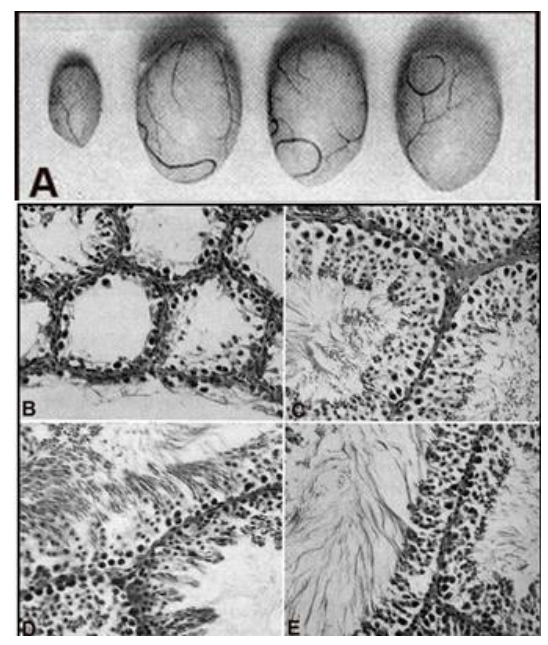

Fig. 1 Gross and histological images of the testes of Syrian hamsters.

Hamsters were kept under either short days (SD) (light:dark cycle of 8:16) or long days (LD) (light:dark cycle of 16:8) and either sham operated or subjected to pinealectomy or sympathetic denervation of the pineal gland (A). From left to right: an atrophic testis of an SD-exposed, sham-operated hamster; a testis of an SD-exposed, pinealectomized hamster; a testis of a shortday exposed hamster in which the pineal gland had been sympathetically denervated and a testis of a hamster kept under LD conditions. Exposure duration was 10 weeks. The SD atrophic testis had a thin germinal epithelium and no ongoing spermatogenesis (B). $C, D$, and $E$ are histological images of the large testes shown in A. Each testis had a thick germinal epithelium that was spermatogenetically active. Female hamsters exposed to SD or LD with/without pinealectomy or pineal denervation are similarly impacted. Several other species of hamster exhibited similar responses to these treatments.

These early studies preceded the introduction of dependable radioimmunoassays for the assessment of reproductively-active hormones (36). So, these measures were not reported in the initial papers. When appropriate antibodies became available, however, the changes in pituitary and plasma gonadotropin and prolactin levels were found to be consistent with the changes in the peripheral reproductive organs (37-41).

The initial publications in 1965 and 1966 unequivocally documenting the marked ability of pinealectomy to restore normal testicular and ovarian function in short day-exposed hamsters $(30,31)$ were met with considerable skepticism by some in the scientific community. Prior to those reports, which uncovered a profound effect of the pineal gland on reproduction, the reproductive changes associated with surgical removal of the pineal gland were slight and inconsistent $(2-5,7,8)$. There were several reasons for the skepticism. In part, this was related to the notion that surgical removal of the pineal gland, which involves opening the skull and exposing the brain, leads to significant damage to the surrounding neural tissue, which induces a change in the function of hypothalamo-pituitary axis leading a shutdown of reproductive capacity. Parenthetically, I recall being challenged after a presentation at a scientific meeting in San Francisco in 1967 by a well-known endocrinologist (the name of the individual is 
intentionally withheld). He and other skeptics had misunderstood, however, that our study showed that pineal removal prevented rather than caused involution of the peripheral reproductive organs. Also, we had designed and published a method of pinealectomy that minimized neural damage (33). Moreover, it was not necessary to open the skull, i.e., perform a pinealectomy, to reduce the inhibitory actions of the pineal on reproduction. Simple sympathetic denervation of the pineal gland by surgical removal of the superior cervical ganglia was equally as effective as pinealectomy in negating the short-day effects.

A second unanticipated issue was the use of short-day exposure to promote gonadal atrophy. The editor of the Yearbook of Endocrinology, a publication that highlighted novel findings in the field each year, questioned whether the use of such "extreme" photoperiods were physiologically meaningful. The editor (name withheld) had clearly forgotten that many species, especially those at temperate and Arctic latitudes, experience marked variations in day lengths on an annual basis. Moreover, there are many hibernators, including the species of hamster used in the initial studies that experience very long periods of total darkness each winter.

This criticism again surfaced in 1970 when I was considering moving from the University of Rochester (New York) to the University of Texas Health Science Center at San Antonio. During my interview, I visited the Vivarium (now named Laboratory Animal Medicine) and because of my interest in the photoperiodic control of reproduction, I asked if any of the animal rooms had windows so I could take advantage of natural day lengths. The director (name withheld) of the Vivarium questioned why I would want to expose animals to such "unnatural" light:dark cycles. $\mathrm{He}$, like some others, had been inculcated with the idea that uniformly controlled long days was natural for all animals all the time.

The final incredulity arose because of the species used. Previously, investigators primarily examined the endocrine aspects of the pineal gland in laboratory rats, and to a lesser extent, in mice. At the time, the use of the hamster for such studies was considered unusual and individuals questioned how important the findings would be generally. Ironically, we had selected the hamster for study since, at the time, it was considered an "outlier" and it was a hibernator.

In the present day, it is difficult to imagine that the issues raised would be a concern to some individuals who learned of the findings. There was also a group of well-known scientists who quickly accepted the results. The names of these individuals will be disclosed: Ernie Knobil (then at the University of Pittsburg), Vernon Mountcastle (Johns Hopkins), William Hansel (Cornell), Vaughan Citchlow (then at Baylor) and Charles "Tom" Sawyer (University of California at Los Angeles). As a young scientist (I had earned my degree in 1964), recognition of this work by these individuals was highly gratifying and was an aid in my scientific advancement. By 1970, the use of a "strange" species (the Syrian hamster) and "extreme" photoperiods were no longer issues for most individuals.

Syrian hamsters have a crepuscular activity pattern, are opportunistic hibernators and are highly seasonal in terms of their reproduction with both males and females being sexually capable from April to September. In their home range in the Middle East, these animals experience day lengths that fall below 11 hours of light in the winter and exceed 13 hours of daylight in the summer. Thus, the different day lengths that determine the reproductive status of laboratory-maintained Syrian hamsters had applicability to these animals in their natural habitat. Thus, when it was first observed that there is a link between photoperiod length and reproduction, we predicted that seasonally-changing day lengths drive, via the pineal gland, the circannual reproductive cycles of this species (30). 
This was confirmed when Syrian hamsters were maintained under natural day lengths and temperature conditions throughout the winter months at a north latitude like that of their home range in the wild; hence, during the short winter days, the reproductive organs of the intact hamsters collapsed while those that were pinealectomized remained functional, similar to animals during the long days of summer (42). This study also showed that seasonal changes in ambient temperature played no significant role in influencing their reproductive cycle. Of interest, also, was that when functionally competent, pinealectomized female and male animals were allowed to mate during the winter months, consistent with their reproductive status, pregnancy occurred and normal pups were delivered (43). Presumably, because of the harsh environmental conditions, however, the young did not survive to weaning. This illustrates the essential nature of seasonal reproduction, which ensures the young are normally born during the spring and summer months, which are maximally conducive to the survival of the offspring (44). Seasonal reproduction is a critical strategy that optimizes the survival of the newborns and, therefore, contributes to the maintenance of the species.

While it was clear that reduced photoperiod lengths, such as occur during the winter months, are associated with infertility in Syrian hamsters and that this suppression requires an intact and functional pineal gland (30-32), proving that melatonin was the responsible agent mediating this inhibitory response proved somewhat more challenging. In 1974, a report was published showing that continually-available melatonin from an implanted subcutaneous reservoir prevented, like pinealectomy, the short day-mediated gonadal involution in the Syrian hamster (45). Considering, what was known at the time, it was difficult to conclude that melatonin was the antigonadotropic factor in this species because it prevented the action it was thought to induce. An explanation for this unanticipated response has not yet been satisfactorily resolved but may be related to the down regulation of the melatonin receptors, due to continuously available melatonin from the subcutaneous reservoir, that mediate the actions of the indoleamine at the level of the hypothalamus $(46,47)$. Making the receptors insensitive to their own ligand would render melatonin, from any source, ineffective in modulating reproduction.

Within a decade, however, melatonin was proven to be the agent that caused the reproductive organs of the Syrian hamster to undergo involution when they were maintained under short-day conditions. Moreover, it was shown that it was the duration of elevated melatonin, rather than any other factor (e.g., amplitude of the melatonin peak or high melatonin levels overlapping a sensitivity period of the hypothalamic melatonin receptors) that accounted for the obvious infertility. When long-day exposed, reproductively active Syrian hamsters were given daily melatonin injections in the late light period, the exogenously administered melatonin synergized with the endogenous melatonin during darkness thereby prolonging the duration of melatonin exposure which then promoted gonadal quiescence $(48,49)$.

On the basis of the published data, the consensus is that seasonal changes in reproductive competence in the Syrian hamster are driven by the seasonally-changing duration of elevated melatonin such that during long summer days the nighttime rise in melatonin is brief and, therefore, inadequate to induce reproductive collapse. As winter approaches, however, the lengthy nights allow for a long duration melatonin signal, which then mediates reproductive regression (Fig. 2) (50). This ensures that Syrian hamsters are incapable of breeding and delivering young during the winter months when harsh environmental conditions could jeopardize the survival of the newborns (43). 


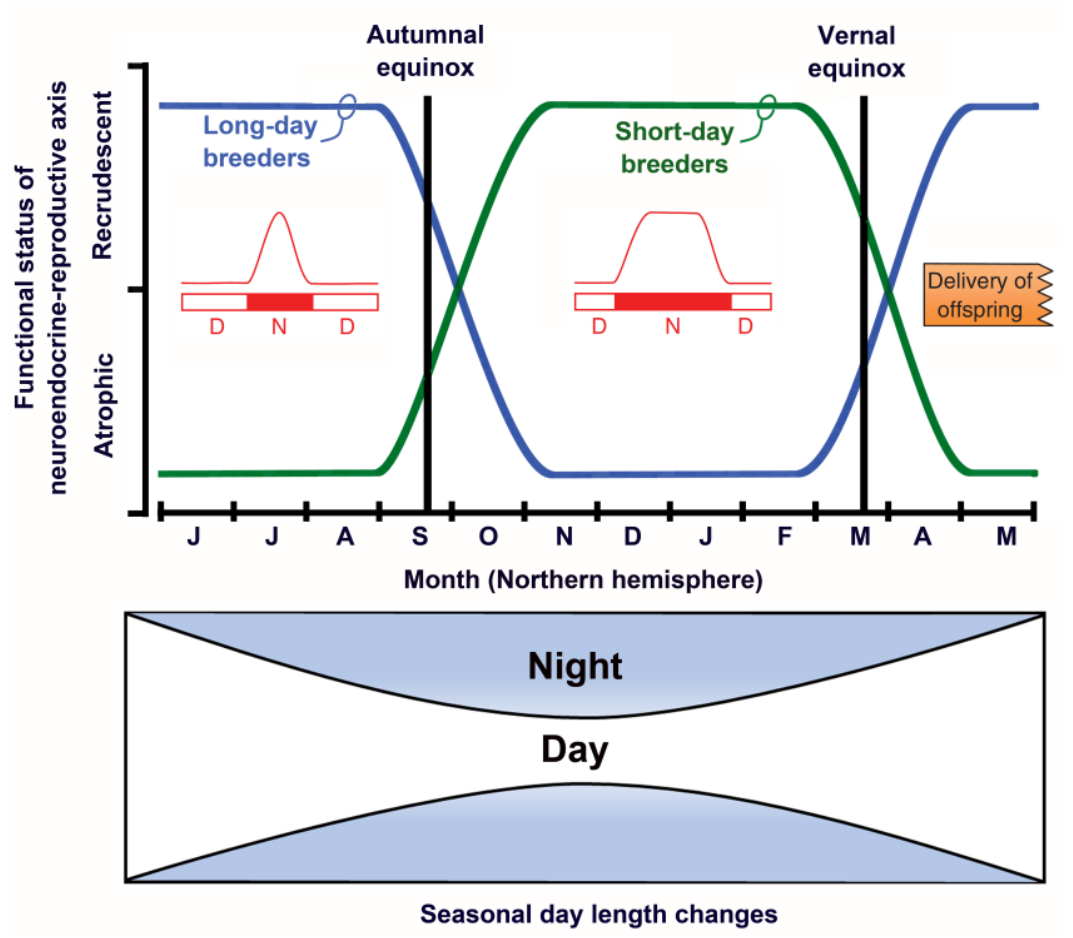

Fig. 2 Seasonal changes in the reproductive capacity of either long day (LD) or short day (SD) breeding mammals.

Long-day breeders experience gonadal atrophy as fall/winter approaches due to the increasingly shortening day lengths (bottom illustration) and the increasing duration of nocturnal melatonin levels (red images). Conversely, SD breeders are reproductively incompetent during the long days of the summer and experience testis/ovarian recrudescence as the days shorten in length and the duration of the melatonin peak is prolonged. In both categories of breeders, the opposite responses occur in the spring as the day lengths change in the opposite direction. Both LD and SD breeders deliver their young in the spring and summer, a time when the survival of the offspring is improved due to favorable environmental conditions. Seasonal fluctuations in day length are especially important for determining the reproductive state of mammals that normally inhabit temperate or polar environments. If species are transferred from the northern to the southern hemisphere, or vice versa, their annual cycles of reproduction change accordingly due to inversion of the photoperiodic changes. Some LD breeders are also hibernators; in this case, they are in total darkness throughout the season when their gonads are atrophic. As spring approaches, but before the emergence from hibernation, the gonads begin to grow (become recrudescent) by becoming refractory to lack of light and the prolonged daily melatonin rise. The molecular basis of the onset of refractoriness remains unknown but it ensures that, at the time these species emerge from hibernation, they are already sexually competent ensuring that the progeny are born in the spring and early summer. Revised and redrawn from (55).

From the foregoing discussion, the reader may be left with the impression that melatonin is always inhibitory to the neuroendocrine-reproductive axis and functions in the same manner in all seasonal breeders. This is far from the case. To consider the Syrian hamster as a prototypical 
species as to how melatonin functions in the control of reproduction in other seasonal breeders would be an error. Indeed, there are a number of examples of so-called antigonadal and progonadal actions of melatonin in the same species $(51,52)$ and in some mammals where melatonin is actually exclusively required to stimulate reproduction $(53,54)$. Contributions related to these seemingly contradictory responses have been provided by a widely diverse group of reproductive biologists leaving no doubt that what is good for one species may not be good for another.

To be sure, melatonin-related information garnered from studies on Syrian hamsters cannot be reliably translated to other mammals, or even to other long day-breeding hamster species. An obvious example that is seemingly in conflict in terms of what melatonin does in the long daybreeding. Syrian hamster is the short-day breeders where melatonin is equally important in maintaining seasonal reproductive rhythmicity.

Thus, melatonin cannot be classified as being either an antigonadal or a progonadal agent. Rather, it is our contention that the melatonin rhythm is a passive signal that provides each species with time-of-year information. The "decision" as to how this message is used is the function of the individual species (55). In some cases, the melatonin duration signal is essentially ignored by the neuroendocrine-reproductive axis, e.g., in the laboratory rat. In other animals, it is a major signal that leads to the collapse of the reproductive organs, e.g., in the Syrian hamster and likely in many other long day-breeders $(51,52)$. Finally, in species that mate during the short winter days, the prolonged nighttime melatonin message promotes growth and function of the reproductive organs, e.g., in deer (56), and many species of sheep (57). What this means is that, as with other actions of melatonin, its function is context specific (58) with the judgment as to how the signal is used being determined by the cells receiving the information. Melatonin does not "force" changes in seasonal reproductive physiology, it merely provides information related to time of year, i.e., it functions as a calendar (59), with the particular species using the information to its physiological advantage.

Since many are highly photoperiodic, several hamster species have been extensively utilized to define the role of the circadian melatonin rhythm in relation to their seasonal reproductive pattern (60-62). This field has been exploited by a large group of excellent scientists who have provided significant clarification of the responses that occur (63-65) and also about the mechanisms involved (47,66-70) The rather small size of rodents has made it more difficult to examine the hypothalamic and pituitary processes involved. Thus, in the last two decades many individuals have used larger species, e.g., ungulates, to examine the neural mechanisms by which melatonin modulates seasonal reproduction; as a result, the specific mechanisms by which circulating melatonin interacts with the cells of the mediobasal hypothalamus and the underlying pituitary tissue comes from investigations that have used a variety of species and both long-day and short-day breeders. Many of the associated findings are summarized in the subsequent sections of this report.

Seasonal reproduction, with the timing of the delivery of the young being the determining factor as to when mammals are fecund, is critical to the survival of the offspring and possibly of the species as well. If animals were capable of indiscriminate mating throughout the year, especially those inhabiting the temperate and polar regions, delivery would often occur in less than optimal seasons which would likely result in even a greater loss of newborns than occurs normally and a major waste of metabolic resources. As an example, the precise nature of the time of calving in reindeer, a species that only inhabits high latitudes, is critical for the maturation of 
the calves before the next winter season (71). This may be threatened with the global climate change, which seems to spread the period of calving in reindeer (72).

The regular annual reproductive cycles are also in jeopardy because of the widespread deployment of artificial light sources. The circadian melatonin rhythm provides precise information to mammals, which allows them to distinguish the season and, therefore, the appropriate time to mate. Any factor that disrupts the daily melatonin cycle would likewise provide inappropriate seasonal information. A major factor that jeopardizes a normal melatonin rhythm is light at night (73). The consequences of such a disruption have already been reported in one mammal. In a population of tammar wallabies on a military base in Australia that is artificially lit a night, birthing of the young has spread over a much longer period compared to the time of delivery of wallabies inhibiting a wilder environment where there was no artificial light contamination (74).

\section{MECHANISMS GOVERNING SEASONAL REPRODUCTION}

For both long-day (e.g., hamsters) and short-day (e.g., sheep) breeding mammals, accurate timing of the delivery of the offspring is an essential feature that, in many temperate and polarresiding species, is governed by the regularly fluctuating seasonal photoperiod due to the tilt of the Earth's axis accompanied by its rotation around the sun. Since that regular environmental change has been stably maintained for millions of years (although the Earth's rotation is slowing ever so slightly), it is not unexpected that both short-lived and long-lived seasonal reproducers evolved a means to use that information to synchronize their breeding activity to improve offspring and species survival. One way of doing this was for mammals to develop a system of capturing photoperiod information, measuring the duration of the daily light period, transducing that information into a humoral message, transferring that message to the cells that guide reproductive physiology, which then dictates the status of the peripheral reproductive organs.

One way of doing this was for mammals to develop a means of capturing photoperiodic information which was accomplished with the evolution of specialized cells in the retina, the intrinsically photoreceptive ganglion cells (ipRGC) (75), that primarily respond to a rather restricted portion of the visible spectrum, i.e., especially blue wavelengths (76). This information is then transferred to the central biological clock, the suprachiasmatic nuclei (SCN) (77), which via the sympathetic nervous system, conveys that information to the pineal gland (78) where it shuts down the synthesis of the humoral agent, melatonin (79). In the absence of this lightmediated neural message, the pineal gears up to generate melatonin which it releases into the cerebrospinal fluid (CSF) and into the blood (80). This pineal secretory product makes its way to the regulatory centers that determine the functional state of the reproduction organs, the pars tuberalis of the pituitary and the hypothalamus (81). Both short-day and long-day breeders seem to use the same complex system to determine annual cycles of fecundity. At the level of the hypothalamo-pituitary axis, melatonin induces different cellular processes, depending on the nocturnal duration of the incoming message (melatonin). Much of what is known about the cellular and molecular events that melatonin promotes at the hypothalamo-pituitary complex has come within the last 20 years (82-84).

Some aspects of the regulatory processes crucial to seasonal reproduction are better understood than others with the majority of the research, thus far, being concentrated on means by which the same melatonin signal either causes the gonads to enlarge (in short-day breeders) or to the regress (in long-day breeders). Other aspects, such as the ability of the system to, 
eventually, completely ignore the signal conveyed by the circadian melatonin rhythm, an event referred to as being refractory or photorefractory (Fig. 2) (85-87), is not well investigated and is poorly understood.

Transferring the melatonin signal from the pineal gland to the hypothalamo-hypophyseal axis has historically been considered to be via the blood vascular system $(83,84,87)$. While this option has not been disproven, it is our contention that, rather than the circadian melatonin cycle in the blood, it is the melatonin rhythm in the CSF that is critical for regulation of seasonal reproduction (80). The reasons for this are as follows: a), the amplitude of the CSF melatonin rise is much greater (up to 10-fold higher) than that in the blood. This being the case, the high concentration of melatonin in the CSF would overwhelm and likely negate the impact of the blood melatonin signal and, b), the CSF melatonin rhythm is much more precise (in terms of "on" and "off") than that of the blood and, therefore, would provide a more accurate depiction of night length. The CSF melatonin rhythm is likely more accurately preserved because of its rapid release into the third ventricle via the pineal recess $(80,88-90)$ or via the suprahabenular recess (91). Once in the CSF, melatonin quickly percolates through the third ventricle into the infundibular recess where, we theorize, it is absorbed by tanycytes (Fig. 3) (92). The long basal processes of these cells transport the melatonin to the responsive cells of the pars tuberalis (PT) and elsewhere (80). Alternatively, melatonin present in the CSF of the third ventricle could merely diffuse from the ventricle to the nearby PT. At the level of the PT, melatonin, depending on the cell type, may or may not interact with melatonin receptors $(87,93)$.

The PT, a portion of the adenohypophysis which remained a functional mystery for many decades, is now known to be a critical interface for reading the light:dark-dependent melatonin rhythm (93). The PT, on the base of the hypothalamus, is near the median eminence, which contains the primary portal capillaries, and also remains physically attached to the pars distalis (PD). The cells of the PT are of several types the most abundant of which are referred to as PTspecific cells. Present in the PT are so-called follicular cells, which do not contain distinguishable secretory granules and cells reminiscent of those in the pars distalis (PD), which have an abundance of secretory granules. The PT-specific cells also have numerous membrane melatonin receptors $(94,95)$. In contrast, cells of the PD only possess melatonin receptors during a short period of fetal development (96). The PT-specific cells also, importantly, are immunoreactive for two important molecules, i.e., the beta-subunit of thyrotropin (TSH) and the common glycoprotein alpha subunit (CGA) (84). These are under control of the photoperiodic message as signaled by the circadian melatonin rhythm $(97,98)$.

After receiving information related to time of day/time of year as expressed in the daily melatonin cycle, the PT cells release molecules that move in both a retrograde (to the mediobasal hypothalamus) and an anterograde (to the PD) manner to refine processes related to seasonal reproduction (87,92). The major retrograde messenger is TSH (99). TSH acts on tanycytes, specialized ependymal cells that co-locate with regular ependymal cells in the infundibular recess, where it acts on TSH receptors to control both type 2 (Dio2) and type 3 (Dio3) deiodinase activities (100). Long photoperiods (short melatonin signaling at the PT) lead to the conversion of thyroxine (T4) to triiodothyronine (T3) via a rise in Dio2 activity (87). T3 promotes the production of Rfamides, which include kisspeptin 1 (KISS1) (and its receptor, GPR54) and related peptides; these agents function as neuroendocrine mediators of seasonal reproduction by controlling the release of gonadotropin-releasing hormone $(\mathrm{GnRH})$ into the primary portal plexus in the median eminence in a large number of species (99). Once in the primary portal plexus, 
GnRH gains access to the gonadotrophs of the PD after its transport through long portal veins in the pituitary stalk and its diffusion out of the secondary portal plexus.

If the retrograde transport of TSH utilizes the basal process of the infundibular tanycytes, they may be the same tanycyte processes that theoretically move melatonin from the CSF to the PT. Axons of neurons possess transport proteins that aid in anterograde (kinesin) and retrograde (dynein) movement of molecules, etc. (101). Whether similar transport proteins exist in the basal processes of tanycytes has not been adequately defined. In addition to TSH, there may be other retrograde messengers that determine Dio2 activity in the tanycytes, e.g., neuromedin U, which is also produced in the PD $(102,103)$.

Eyes-absent (EYA) proteins are also well conserved across species in the PT. They may be critical transcriptional co-activators of TSH expression in the PT; if so, they would be important upstream modulators of PT-specific thyrotrophs (104).

Anterograde mediators from the PT to the PD where they influence production and the discharge of prolactin are collectively referred to as tuberalins (93). They are released from the PT in response to photoperiod manipulations and melatonin administration; their discharge is forskolin-dependent. Molecules that have been at least tentatively identified as tuberalins include tachykinin 1 (TAC1), neurokinin A (NKA) (105), vascular endothelial growth factor (106) and endocannabinoids (107), all of which may release prolactin from lactotrophs in the PD (Fig. 3).

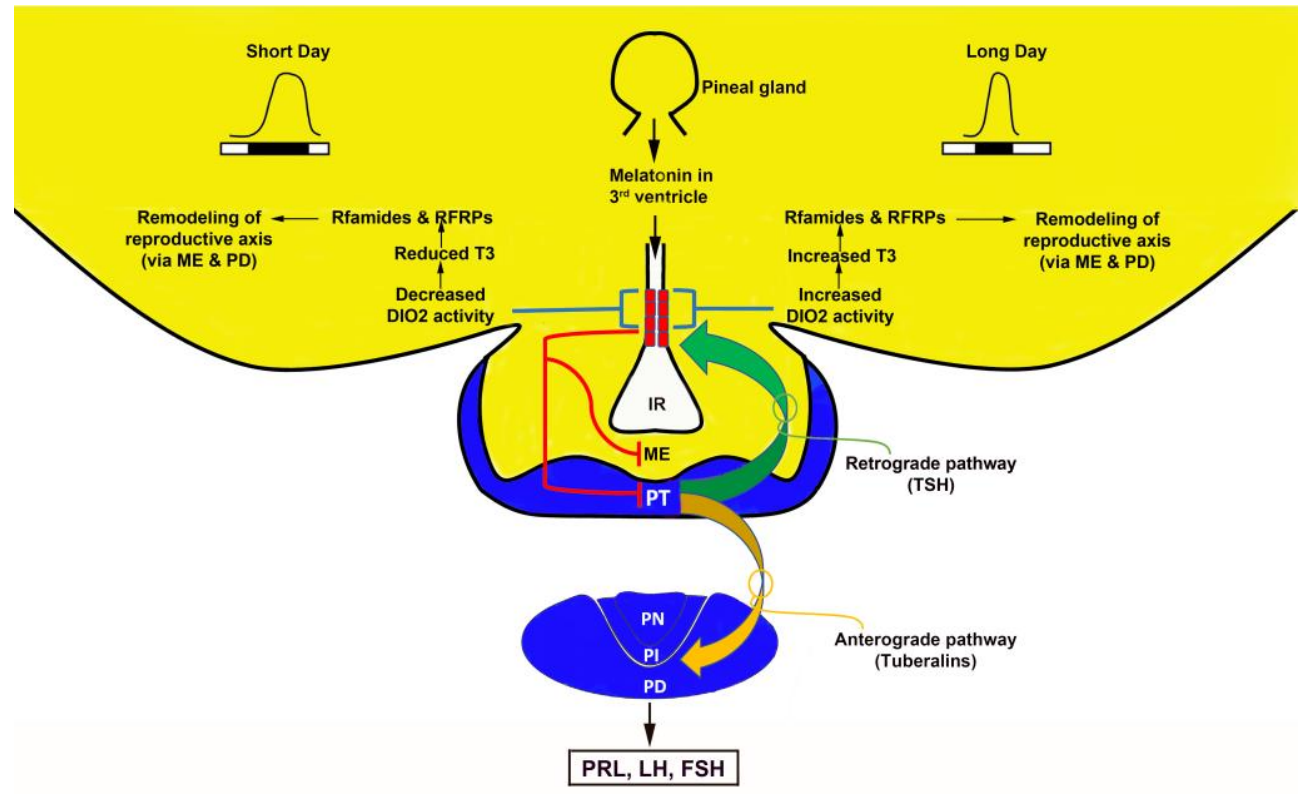

Fig. 3 The mechanisms governing the regulation of the hypothalamo-hypophyseo-gonadal axis in short-day and long-day breeders are illustrated in this figure.

It is our contention that melatonin released from the pineal gland directly into the third ventricle cerebrospinal fluid (CSF) is the signal that determines the shut down or activation of the processes that regulate the active/inactive state of the peripheral reproductive organs in seasonal breeding mammals. Thus, we hypothesize that the CSF melatonin rhythm, rather than the cycle in the blood, controls the hypothalamus because it is a much stronger signal (10-fold higher nocturnal amplitude) and provides a more precise on/off message. Once released into the pineal recess, melatonin quickly diffuses into the CSF of the infundibular recess where it gains 
access to the pars tuberalis (PT) of the adenohypophysis via tanycytes or by simple diffusion. After melatonin makes contact with cells of the PT, these cells send messages in both a retrograde and anterograde manner. The retrograde message, which is believed to be TSH, travels either via processes of the tanycytes or by simple diffusion; in tanycytes, TSH regulates enzymes that control the conversion of the thyroxine (T4) to triiodothyronine (T3); the tanycytes line the infundibular recess of the third ventricle. The T3 then modulates the activities of a series of messengers, which eventually mediate the release of gonadotropin-releasing hormone (GnRH) into the primary portal plexus located in the median eminence. The details of many of the intervening events remain poorly described. The anterograde message, which may include several so-called "tuberalins", are released from PT cells and diffuse into the adjacent median eminence to also enter the primary portal plexus. Once in the primary portal plexus, GnRH and the tuberalins trickle down the long portal veins to enter the secondary portal plexus in the pars distalis (PD) after which they escape the circulation and modulate the release of luteinizing hormone and follicle stimulating hormone from gonadotrophs and prolactin from lactotrophs, which combine to determine the functional state of the peripheral reproductive organs. The text should be consulted for further details. Additionally, melatonin extracted from the blood and especially that produced locally in the peripheral reproductive organs has protective effects at the level of the gonads, gametes, and adnexa. The authors re-iterate that some of the processes described remain speculative and/or poorly understood. IR = infundibular recess of the third ventricle; $P I=$ pars intermediate of the anterior pituitary; $P N=$ pars nervosa; $R F R P=$ Rfamide-related peptides. Tanycytes and their basal processes are represented in red. Figure drawn from data presented in (104) and (107).

\section{CONCLUDING REMARKS}

It has been more than 50 years since the first report showing that surgical removal or sympathetic denervation of the pineal gland prevented short-day mediated regression of the peripheral reproductive organs of male and female Syrian hamsters. Soon after these findings were reported, it was observed that the neuroendocrine-reproductive axis of other hamster species also remained highly functional after pinealectomy even when they were maintained under a reproductively-inhibitory photoperiod. Within the same timeframe, it was documented that melatonin is the pineal agent responsible for the waxing and waning of reproductive physiology on an annual basis. This is consistent with the observations which confirmed that the duration of the daily nighttime melatonin rise is controlled by the duration of the daily dark period. These early studies served as the foundation for numerous subsequent publications related to the mechanisms by which melatonin achieves this action.

It also soon became apparent, however, that many species rather than breeding during the lengthening spring and long summer days, actually successfully mate when the day lengths are shortest and the nightly melatonin peak is long (Fig. 3). Thus, the actions of melatonin on the neuroendocrine-reproductive axis cannot be classified as being either antigonadal or progonadal. Rather, the melatonin signal is a passive message that provides animals with calendar information with the "decision" as to how to use the information being left to the specific species.

The centerpiece of seasonal reproduction is the timing of delivery of the progeny. The most propitious time for this to occur is when temperatures are most favorable and food resources are most abundant, i.e., spring and summer. Most species abide by this strategy. This requires that 
species that have a very short (several weeks) or long (10-12 months) gestation be long-day breeders while those with gestation periods of 5-7 months be short-day breeders. Of special interest is that the same seasonal changing photoperiod and melatonin message drives both longand short-day breeding cycles.

In lieu of the photoperiod, there are other environmental factors that change annually and could have been used to identify the seasons of the year, e.g., temperature, rainfall, food availability, etc. These changes, however, provide much less precise information than does the highly regularly-recurring light:dark cycle. So the evolution of an organ, the pineal gland, that measures day length was the rational choice. Although the rotation of the Earth on its axis is slowing and, within a life time days are becoming imperceptibly longer, regular seasonal day length changes have persisted for millennia.

Given that day lengths are becoming longer, it may be more than a coincidence that the master biological clock, i.e., the SCN, is not precisely set at 24 hours. If the SCN was hardwired to a 24-hour period and not synchronized by the rising and setting of the sun, over eons there could be a disconnect between day length and the unchangeable rhythm of the clock.

While the ability of the melatonin cycle to synchronize seasonal reproductive events in mammals is well established, this function of melatonin has a rather short evolutionary history (perhaps about 65-70 million years). Melatonin has many functions that preceded its circadian and seasonal functions as is apparent in present-day mammals. Melatonin has been around for an estimated 2.5 to 3.2 billion years judging from its presence in bacteria (108). We have surmised that the original function of melatonin was as an antioxidant and, additionally, it has acquired many other functions during its very long evolutionary history (109-111). Also, since it has cohabitated intracellularly with other evolutionary ancient molecules for a very long time, it has "learned" to cooperate with them in influencing cellular physiology (112).

The findings that confirm the actions of the melatonin rhythm in terms of mediating the seasonal reproductive cycle via regulatory effects on the hypothalamo-hypophyseal axis does not mean that it has no functional significance on reproductive-related physiology in non-seasonal breeders. Due to its direct free radical scavenging actions and its indirect antioxidant activities (113-116), melatonin protects the ovary and testis as well as the gametes from oxidative damage. These functions of melatonin at the peripheral level are important since they assure successful fertilization, proper implantation and the delivery of normal offspring (116-118). These protective effects of melatonin on the peripheral reproductive organs occur in both seasonal and non-seasonal breeders.

\section{CONFLICT OF INTERESTS}

The authors declare that there are no conflicts of interest.

\section{REFERENCES}

1. Lerner AB, Case JD, Takahashi Y, et al. (1958) Isolation of melatonin, the pineal gland factor that lightens melanocytes. J. Am. Chem. Soc. 80: 2587.

2. Kitay JI, Altschule MD. (1954) The Pineal Gland. Harvard University Press. Cambridge, MA.

3. Thieblot L, Le Bars. (1954) La Glande Pineale ou Epiphyse. Librairie Malonine SA, Paris. 
4. Foa C. (1912) Hypertrophie des testicules et de la erete, apres extirpation de la glande pineale. Arch. Ital. Biol. 57: 233-252.

5. Izawa Y. (1926) On some anatomical changes which follow removal of the pineal body from both sexes of the immature albino rat. Am. J. Physiol. 77: 126-139.

6. Bing JF, Globus JH, Simon H. (1938) Pubertas praecox: a survey of the reported cases and verified anatomical findings, with particular reference to tumors of the pineal body. $J$. Mt. Sinai Hosp. 4: 935-965.

7. Kitay JI. (1954) Effect of pinealectomy on ovary weight in immature rats. Endocrinology 54:114-116.

8. Wragg LE. (1957) Effect of pinealectomy in the newborn rat. Am. J. Anat. 120: 391-402.

9. McCord CP, Allen FP. (1917) Evidences associating pineal gland function with alterations with skin pigmentation. J. Exp. Zool. 23: 207-224.

10. Lerner AB, Case JD. (1959) Pigment cell regulatory factors. J. Invest. Dermatol. 32: 211219.

11. Sanchez-Barcelo E, Rueda N, Mediavilla MD, et al. (2017) Clinical uses of melatonin in neurological diseases and mental and behavioral disorders. Curr. Med. Chem. 24: 38513878.

12. Slominski AT, Hardeland R, Zmijewski MA, et al. (2018) Melatonin: a cutaneous perspective on its production, metabolism and functions. J. Invest. Dermatol. 138: 490-499.

13. Axelrod J, Weissbach H. (1960) Enzymatic O-methylation of $\mathrm{N}$-acetylserotonin to melatonin. Science 131: 1312.

14. Axelrod J, Weissbach H. (1961) Purification and properties of hydroxyindole-Omethyltransferase. J. Biol. Chem. 236: 211-213.

15. Wurtman RJ, Axelrod J. (1965) The formation, metabolism, and physiological effects of melatonin in mammals. Progr. Brain Res. 10: 520-529.

16. Quay WB. (1963) Circadian rhythm in rat pineal serotonin and its modification by estrous cycle and photoperiod. Gen. Comp. Endocrinol. 3: 473-479.

17. Wurtman RJ, Axelrod J, Phillips LS. (1963) Melatonin synthesis in the pineal gland: control by light. Science 142: 1071-1073.

18. Axelrod J, Wurtman RJ, Winget CM. (1964) Melatonin synthesis in the hen pineal gland and its control by light. Nature 201: 1134 .

19. Quay WB. (1964) Circadian and estrous rhythms in pineal melatonin and hydroxyindole-3acetic acid. Proc. Soc. Exp. Biol. Med. 115: 710-713.

20. Quay WB. (1956) Volumetric and cytologic variation in the pineal body of Peromyscus leucopus (rodentia) with respect of sex, captivity and day-length. J. Morphol. 98: 471-478.

21. Mogler K-H R. (1958) Das Endokrine System des Syrischen Goldhamster unter Beriicksichtigung des Naturalichen und Experimentellen Winterschlafs. Zeit Mosphol Okeol Tiere 47: 267-308.

22. Fiske VM, Bryant GK, Putman J. (1960) Effect of light on the weight of the pineal in the rat. Endocrinology 66: 489-495.

23. Wurtman RJ, Axelrod J. (1965) The pineal gland. Sci. Am. 213: 50-60.

24. Klein DC, Weller JL. (1970) Indole metabolism in the pineal gland: a circadian rhythm in Nacetyltransferase. Science 169: 1093-1095.

25. Pelham RW, Ralph CL, Campbell IM. (1972) Mass spectral identification of melatonin in blood. Biochem. Biophys. Res. Commun. 46: 1236-1241. 
26. Pelham RW. (1975) A serum melatonin rhythm in chickens and its abolition by pinealectomy. Endocrinology 96: 543-546.

27. Vaughan GM, Pelham RW, Pang SF, et al. (1976) Nocturnal elevation of plasm melatonin and urinary 5-hydroxyindoleacetic acid in young men: attempts at modification by brief changes in environmental lighting and sleep and autonomic drugs. J. Clin. Endocrinol. Metab. 42: 752-764.

28. Chu EW, Wurtman RJ, Axelrod J. (1964) An inhibitory effect of melatonin on the estrous phase of the estrous cycle of the rodent. Endocrinology 75: 238-244.

29. Wurtman RJ, Axelrod J, Chu EW. (1964) The relation between melatonin, a pineal substance, and the effects of light on the rat gonad. Ann. N. Y. Acad. Sci. 117: 228-230.

30. Hoffman RA, Reiter RJ. (1965) Pineal gland: influence on gonads of male hamsters. Science 148: 1609-1611.

31. Hoffman RA, Reiter RJ. (1966) Influence of compensatory mechanisms and the pineal upon light-induced gonadal atrophy in male hamsters. Nature 207: 638-639.

32. Reiter RJ, Hester RJ. (1966) Interrelationships of the pineal gland, the superior cervical ganglia and the photoperiod in the regulation of the endocrine systems of hamsters. Endocrinology 79: 1168-1170.

33. Hoffman RA, Reiter RJ. (1965) Rapid pinealectomy in hamsters and other small rodents. Anat. Rec. 153: 19-21.

34. Reiter RJ. (1972) Surgical procedures involving the pineal gland which prevent gonadal degeneration in adult male hamsters. Ann. Endocrinol. 33: 341-348.

35. Reiter RJ. (1980) The pineal gland: a regulator of regulators. Progr. Psychobiol. Physiol. Psychol. 9: 323-356.

36. Berson SA, Yalow RS. (1968) General principles of radioimmunoassay. Clin. Chim. Acta. 22: 51-69.

37. Reiter RJ, Johnson LY. (1974) Pineal regulation of immunoreactive luteinizing hormone and prolactin in light-deprived female hamsters. Fertil Steril. 25: 958-964.

38. Reiter RJ, Johnson LY. (1974) Depressant action of the pineal gland on pituitary luteinizing hormone and prolactin in male hamsters. Horm. Res. 5: 311-320.

39. Reiter RJ. (1975) Changes in pituitary prolactin levels of female hamsters as a function of age, photoperiod and pinealectomy. Acta. Endocrinol. 19: 43-50.

40. Stetson MH, Tate-Ostroff B. (1981) Hormonal regulation of the annual reproductive cycle of golden hamsters. Gen. Comp. Endocrinol. 45: 329-344.

41. Tamarkin L, Hutchinson JS, Goldman BD. (1976) Regulation of serum gonadotropins by photoperiod and testicular hormone in the Syrian hamster. Endocrinology 99: 1528-1533.

42. Reiter RJ. (1973) Pineal control of a seasonal reproductive rhythm in male golden hamsters exposed to natural daylight and temperature. Endocrinology 92: 423-430.

43. Reiter RJ. (1974) Influence of pinealectomy on the breeding capability of hamsters maintained under natural photoperiodic and temperature conditions. Neuroendocrinology 13: 366-370.

44. Bronson FH. (1982) Mammalian reproductive strategies: genes, photoperiod and latitude. Reprod. Nutr. Rev. 28: 335-347.

45. Reiter RJ, Vaughan MK, Blask DE, et al. (1974) Melatonin: its inhibition of pineal antigonadotropic activity in male hamsters. Science 185: 1169-1171.

46. Revel FG, Saboureau M, Pevet P, et al. (2006) Melatonin regulates type 2 deiodinase gene expression in the Syrian hamster. Endocrinology 147:4680-4687. 
47. Simonneaux V, Ancel C, Poirel VJ, et al. (2013) Kisspeptins and RFRP-3 act in concert to synchronize rodent reproduction with seasons. Front. Neurosci. 7: 22.

48. Reiter RJ, Blask DE, Johnson LY, et al. (1976) Melatonin inhibition in the male hamster: its dependency on time of day of administration and on an intact and sympathetically innervated pineal gland. Neuroendocrinology 22: 107-116.

49. Tamarkin L, Westrom WK, Hamill AI, et al. (1976) Effect of melatonin on the reproductive systems of male and female Syrian hamsters: a diurnal rhythm in sensitivity to melatonin. Endocrinology 99: 1534-1541.

50. Reiter RJ. (1974) Circannual reproductive rhythms in mammals related to photoperiod and pineal function: a review. Chronobiologia 1: 365-395.

51. Stetson MH, Watson-Whitmyre M. (1986) Effects of exogenous and endogenous melatonin on gonadal function in hamsters. J. Neural Transm. 21: 55-80.

52. Pevet P. (1988) The role of the pineal gland in the photoperiodic control of reproduction in different hamster species. Reprod. Nutr. Rev. 28: 443-458.

53. Carter DS, Hall VD, Tamarkin L, et al. (1982) Pineal is required for testicular maintenance in the Turkish hamster (Mesocricetus brandti). Endocrinology 111: 863-871.

54. Jarjisian SG, Zucker I. (2011) Elimination of short-day melatonin signaling accelerates gonadal recrudescence but does not break refractoriness in male Turkish hamsters. J. Biol. Rhythms 26: 130-135.

55. Reiter RJ, Tan DX, Manchester LC, et al. (2009) Melatonin and reproduction revisited. Biol. Reprod. 81: 445-459.

56. Lincoln GA. (1998) Photoperiod-melatonin relay in deer. Acta. Vet. Hung. 46: 341-356.

57. Karsch FJ, Bittman EL, Foster DL, et al. (1984) Neuroendocrine basis of seasonal reproduction. Rec. Progr. Horm. Res. 40: 185-232.

58. Bizzarri M, Proietti S, Cucina A, et al. (2013) Molecular mechanisms of the pro-apoptotic actions of melatonin in cancer: a review. Exp. Opin. Ther. Targets 17: 1483-1496.

59. Reiter RJ. (1993) The melatonin rhythm: both a clock and a calendar. Experientia 49: 654664.

60. Goldman BD. (1983) The physiology of melatonin in mammals. Pineal Res. Rev. 1: 145-182.

61. Alleva JJ. (1987) The biological clock and the pineal gland: how they control seasonal fertility in the golden hamster. Pineal Res. Rev. 5: 95-133.

62. Glass JD. (1988) Neuroendocrine regulation of seasonal reproduction by the pineal gland and melatonin. Pineal Res. Rev. 6: 239-259.

63. Turek FW. (1977) Antigonadal effect of melatonin in pinealectomized and intact male hamsters. Proc. Soc. Exp. Biol. Med. 155: 31-34.

64. Hoffman K. (1979) Photoperiod, pineal melatonin and reproduction in hamsters. Progr. Brain Res. 52: 397-415.

65. Yellon SM, Tamarkin L, Pratt BL, et al. (1982) Pineal melatonin in the Djungarian hamster: photoperiodic regulation of a circadian rhythm. Endocrinology 111: 488-492.

66. Elliott JA. (1976) Circadian rhythms and photoperiodic time measurement in mammals. Fed. Proc. 35:2 339-2346.

67. Stetson MH, Elliott JA, Menaker M. (1975) Photoperiod regulation of hamster testis: circadian sensitivity to the effects of light. Biol. Reprod. 13: 329-339.

68. Inouye ST, Turek FW. (1986) Horizontal knife cuts either ventral or dorsal to the hypothalamic paraventricular nucleus block testicular regression in golden hamsters maintained in short days. Brain Res. 370: 102-107. 
69. Bernard DJ, Abuav-Nussbaum R, Horton TH, et al. (1999) Photoperiodic effects on gonadotropin-releasing hormone $(\mathrm{GnRH})$ content and the GnRH-immunoreactive neuronal system of male Siberian hamsters. Biol. Reprod. 60: 272-276.

70. Gunduz B, Stetson MH. (2001) A test of the coincidence and duration models of melatonin action in Siberian hamsters. II. The effects of 4- and 8-hr melatonin infusions on testicular development of pinealectomized juvenile Siberian hamsters (Phodopus sungorus). J. Pineal Res. 30: 56-64.

71. Ropstad E. (2000) Reproduction in female reindeer. Anim. Reprod. Sci. 60-61:561-570.

72. Paoli A, Weladji RB, Holand O, et al. (2018) Winter and spring climate conditions influence timing and synchrony of calving in reindeer. PLoS One 13: e195603.

73. Brainard GC, Lewy AJ, Menaker M, et al. Dose-response relationships between light irradiance and the suppression of plasma melatonin in human volunteers. Brain Res. 454: 212-216.

74. Robert KA, Lesku JA, Partecke J, et al. (2015) Artificial light at night desynchronizes strictly seasonal reproduction in a wild mammal. Proc. Royal Sci. 282: 20151745.

75. Lucas RJ, Peirson SN, Berson DM, et al. (2014) Measuring and using light in the melanopsin age. Trends Neurosci. 37: 1-9.

76. Bonmati-Carrion MA, Arguello-Prieto R, Martinez-Madrid MJ, et al. (2014) Protecting the melatonin rhythm through circadian healthy light exposure. Int. J. Mol. Sci. 15: 2344823500.

77. Kim P, Oster H, Lehnert H, et al. (2018) Coupling the circadian clock to homeostasis: the role of period in timing physiology. Endocr. Rev. in press.

78. Lingappa JR, Zigmond RE. (2013) Limited recovery of pineal function after regeneration of preganglionic sympathetic axons: evidence for loss of ganglionic synaptic specificity. $J$. Neurosci 33: 4867-4874.

79. Klein DC. (2007) Arylalkylamine $N$-acetyltransferase: "the timenzyme." J. Biol. Chem. 282: 4233-4237.

80. Reiter RJ, Tan DX, Kim SJ, et al. (2014) Delivery of pineal melatonin to the brain and SCN: role of canaliculi, cerebrospinal fluid, tanycytes and Virchow-Robin perivascular spaces. Brain Struct. Funct. 219: 1873-1887.

81. Jethwa PH, Ebling FJ. (2008) Role of VGF-derived peptides in the control of food intake, body weight and reproduction. Neuroendocrinology 88: 80-87.

82. Wood SH, Laudon A. (2014) Clocks for all seasons: unwinding the roles and mechanisms of circadian and internal timers in the hypothalamus and pituitary. J. Endocrinol. 222: R39-R59.

83. Dardente H, Lomet D, Robert V, et al. (2016) Seasonal breeding in mammals: from basic science to applications and back. Theriogenology 86: 324-332.

84. Korf H-W. (2018) Signaling pathways to and from the hypophysial pars tuberalis, an important center for the control of circadian rhythms. Gen. Comp. Endocrinol. 258: 236-243.

85. Reiter RJ. (1972) Evidence for refractoriness of the pituitary-gonadal axis to the pineal gland in golden hamsters and its implications in annual reproductive rhythms. Anat. Rec. 173: 365371.

86. Stetson MH, Watson-Whitmyre M, Tate-Ostroff B. (1983) Role of the pineal and its hormone melatonin in the termination of photorefractoriness in golden hamsters. Biol. Reprod. 29: 689-696. 
87. Wood S, Laudon A. (2018) The pars tuberalis: the site of the circannual clock in mammals. Gen. Comp. Endocrinol. 258: 222-235.

88. Skinner DC, Malpaux, B. (1999) High melatonin concentrations in the third ventricular cerebrospinal fluid are not due to Galen vein blood recirculating through the choroid plexus. Endocrinology 140: 4399-4405.

89. Tricoire H, Moller M, Chemineau P, et al. (2003) Origin of cerebrospinal fluid melatonin and possible function in the integration of photoperiod. Reproduction Suppl. 61: 311-321.

90. Legros C, Chesneau D, Boutin JA, et al. (2014) Melatonin from cerebrospinal fluid but not from blood reaches sheep cerebral tissues under physiological conditions. J. Neuroendocrinol. 26: 151-163.

91. Sheridon MN, Reiter RJ, Jacobs JJ. (1969) An interesting anatomical relationship between the hamster pineal gland and the ventricular system of the brain. J. Endocrinol. 45: 131-132.

92. Lewis JE, Ebling FJP. (2017) Tanycytes as regulators of seasonal cycles in neuroendocrine function. Front. Neurol. 8: 79.

93. Dandente H, Klosen P, Pevet P, et al. (2003) MT1 melatonin receptor mRNA expressing cells in the pars tuberalis of the European hamster: effect of photoperiod. J. Neuroendocrinol. 15: 778-786.

94. Klosen P, Bienvenu C, Demarteau O, et al. (2002) The MT1 melatonin receptor and RORbeta receptor are co-localized in specific TSH-immunoreactive cells in the pars tuberalis of the rat pituitary. J. Histochem. Cytochem. 50: 1647-1667.

95. Dardente H, Menet JS, Poirel VJ, et al. (2003) Melatonin induces Cry1 expression in the pars tuberalis of the rat. Brain Res. Mol. Brain Res. 114: 101-106.

96. Vanecek J. (1988) The melatonin receptors in rat ontogenesis. Neuroendocrinology 48: 201203.

97. Bockmann J, Bockers TM, Vennemann B, et al. (1996) Short photoperiod-dependent downregulation of thyrotropin-alpha and -beta in hamsters pars tuberalis-specific cells is prevented by pinealectomy. Endocrinology 137: 1804-1813.

98. Wittkowski W, Bockmann J, Kreutz MR, et al. (1999) Cell and molecular biology of the pars tuberalis of the pituitary. Int. Rev. Cytol. 185: 157-194.

99. Roa J, Tena-Sempere M (2007) KISS-1 system and reproduction: comparative aspects and roles in the control of female gonadotropic axis of mammals. Gen. Comp. Endocrinol. 153: 132-140.

100. Mayeri S, Visser TJ, Darras VM, et al. (2012) Impact of Oatp1c1 deficiency on thyroid hormone metabolism and action in the mouse brain. Endocrinology 153: 1528-1537.

101. Huang CY, Rasband MN. (2018) Axon initial segments: structure, function and disease. Ann. N. Y Acad. Sci. 142: 46-61.

102. Aizawa S, Sakata I, Nagasaka M, et al., (2013) Negative regulation of neuromedin U mRNA expression in the rat pars tuberalis by melatonin. PLoS One 8: e67118.

103. Helfer G, Ross AW, Morgan PJ. (2013) Neuromedin U partly mimics thyroid-stimulating hormone and triggers $\mathrm{Wnt} / \beta$-catenin signaling in the photoperiod response of $\mathrm{F} 344$ rats. J. Neuroendocrinol. 25: 1264-1272.

104. Dardente H, Wipe CA, Birnie MJ, et al. (2010) A molecular switch for photoperiod responsiveness in mammals. Curr. Biol. 20: 2193-2198.

105. Dupre SM, Miredzinska K, Duval CV, et al. (2010) Identification of E4a3 and Tac1 as long day signals in the sheep pituitary. Curr. Biol. 20: 829-835. 
106. Castle-Miller J, Bates DO, Tortonese DJ. (2017) Mechanisms regulating angiogenesis underlie seasonal control of pituitary function. Proc. Natl. Acad. Sci. USA 114: E2514E2523.

107. Yasuo K, Korf H-W. (2011) The hypophysial pars tuberalis transduces photoperiodic signals via multiple pathways and messenger molecules. Gen. Comp. Endocrinol. 172: 15-22.

108. Manchester LC, Poeggler B, Alvares FL, et al. (1995) Melatonin immunoreactivity in the photosynthetic prokaryote Rhodospirillum rubrum: implications for an ancient antioxidant system. Cell Mol. Biol. Res. 41: 391-395.

109. Reiter RJ, Tan DX, Galano A. (2014) Melatonin: exceeding expectations. Physiology (Bethesda) 29: 325-333.

110. Tan DX, Manchester LC, Liu X, et al. (2013) Mitochondria and chloroplasts as the original sites of melatonin synthesis: a hypothesis related to melatonin's primary function in evolution in eukaryotes. J. Pineal Res. 54: 127-138.

111. Reiter RJ, Tan DX, Fuentes-Broto L. (2010) Melatonin: a multitasking molecule. Prog. Brain Res. 181: 127-151.

112. Reiter RJ, Rosales-Corral S, Zhou X, et al. (2017) Role of SIRT3/SOD2 signaling in mediating the antioxidant actions of melatonin in mitochondria. Curr. Trends Endocrinol. 9: 45-49.

113. Tan DX, Manchester LC, Esteban-Zabero E, et al. (2015) Melatonin as a potent and inducible antioxidant: synthesis and metabolism. Molecules 20: 448-454.

114. Manchester LC, Coto-Montes A, Boga JA, et al. (2015) Melatonin: an ancient molecule that makes oxygen metabolically tolerable. J. Pineal Res. 59: 403-419.

115. Reiter RJ, Rosales-Corral S, Tan DX, et al. (2017) Melatonin as a mitochondria-targeted antioxidant: one of evolutions best ideas. Mol. Cell. Life. Sci. 74: 3863-3881.

116. Aversa S, Pelligrino S, Barberi I, et al. (2012) Potential utility of melatonin as an antioxidant during pregnancy and in the perinatal period. J. Matern. Fetal Neonatal Med. 25: 207-221.

117. Reiter RJ, Rosales-Corral SA, Manchester LC, et al. (2013) Peripheral reproductive organ health and melatonin: ready for prime time. Int. J. Mol. Sci. 14: 7231-7272.

118. Cabrian-Perez JA, Casao A, Gonzalez-Arto M, et al. (2014) Melatonin and sperm biology: breaking paradigms. Reprod. Domest. Anim. 49 (Suppl 4): 11-21.

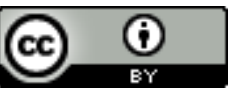

This work is licensed under a Creative Commons Attribution 4.0 International License 